\title{
Compressed $\mathrm{CO}_{2}$ technologies for the recovery of carotenoid-enriched
}

\section{extracts from Dunaliella salina with potential neuroprotective activity}

Mónica Bueno ${ }^{1}$, Clementina Vitali ${ }^{1,2}$, José David Sánchez-Martínez ${ }^{1}$, José Antonio Mendiola $^{1}$, Alejandro Cifuentes ${ }^{1}$, Elena Ibáñez ${ }^{1}$, Miguel Herrero ${ }^{*}$

${ }^{1}$ Laboratory of Foodomics, Institute of Food Science Research, CIAL, CSIC, Nicolás Cabrera 9, 28049 Madrid, Spain.

${ }^{2}$ Unit of Food Science and Nutrition, Faculty of Medicine - Campus Bio-Medico University of Rome, via Álvaro del Portillo 21, 00128 Rome, Italy

*Corresponding author:

Dr. Miguel Herrero, Laboratory of Foodomics, Institute of Food Science Research,

CIAL (CSIC), Nicolás Cabrera 9, 28049 Madrid, Spain,

e-mail:m.herrero@csic.es

Tel.: +34 910017946; fax: +34910017905.

Number of pages: 1

Number of figures: 2

Number of tables: 1 


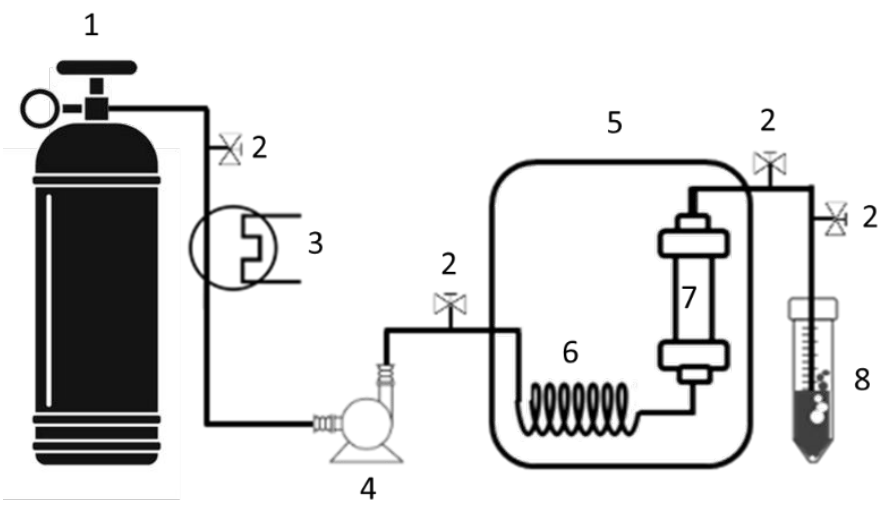

Figure S1: Scheme of the carbon dioxide extraction apparatus: (1) $\mathrm{CO}_{2}$ cylinder, (2) needle valve, (3) chiller, (4) $\mathrm{CO}_{2}$ pump, (5) oven, (6) pre-heat coil, (7) sample cell, (8) collection vessel 

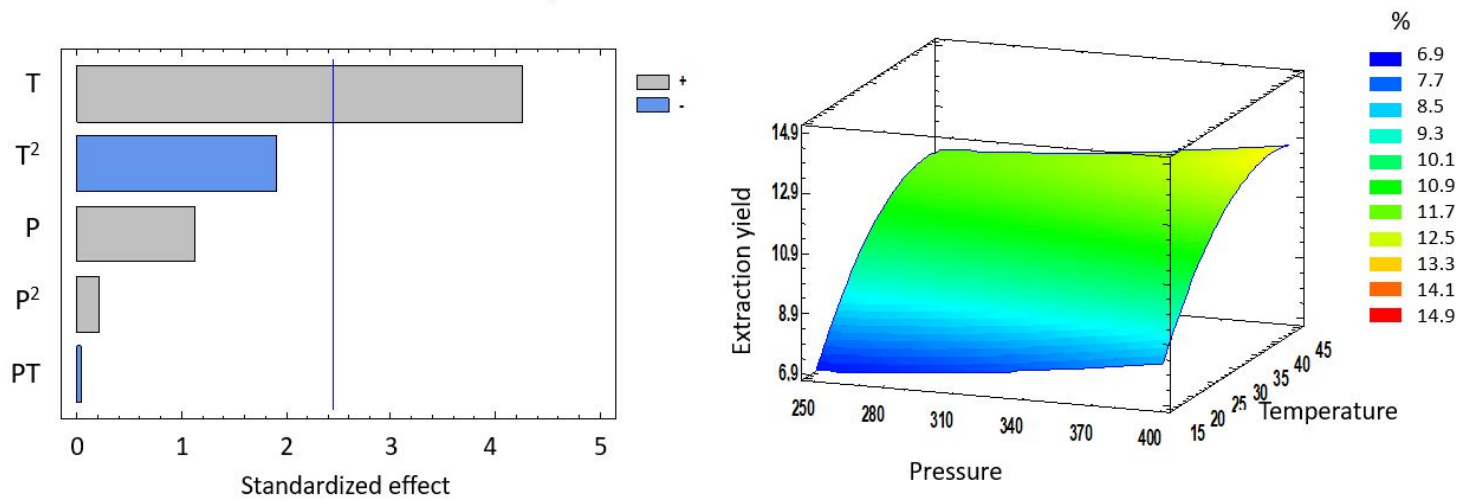

Figure S2: Pareto chart representation (left) and estimated response surface (right) of extraction yield (percentage of extract weight per initial algae weight) as a function of pressure and temperature. 
Table S1: HPLC-UV/Vis calibration curves parameters of carotenoids standards employed for quantification

\begin{tabular}{|c|c|c|c|c|c|}
\hline Compound & $\begin{array}{c}\text { Linearity range } \\
\qquad(\mu \mathrm{g} / \mathrm{mL})\end{array}$ & $\begin{array}{c}\text { LOD } \\
(\mu \mathrm{g} / \mathrm{mL})\end{array}$ & $\begin{array}{c}\text { LOQ } \\
(\mu \mathrm{g} / \mathrm{mL})\end{array}$ & $\begin{array}{c}\text { Linear regression } \\
\text { equation }\end{array}$ & $\mathrm{r}^{2}$ \\
\hline All-trans- $\beta$-carotene & $0.196-26.1$ & $2.22 \times 10^{-2}$ & $7.43 \times 10^{-2}$ & $y=142 x$ & 1.000 \\
\hline Lutein & $3.13-50.0$ & $9.84 \times 10^{-2}$ & 0.328 & $y=13.1 x$ & 0.992 \\
\hline Zeaxanthin & $3.91-31.3$ & $9.90 \times 10^{-2}$ & 0.330 & $\mathrm{y}=45.1 \mathrm{x}$ & 0.999 \\
\hline
\end{tabular}

